Journal Club

Editor's Note: These short, critical reviews of recent papers in the Journal, written exclusively by graduate students or postdoctoral fellows, are intended to summarize the important findings of the paper and provide additional insight and commentary. For more information on the format and purpose of the Journal Club, please see http://www.jneurosci.org/misc/ifa_features.shtml.

\title{
Presynaptic Deficits at Neuromuscular Junctions: A Specific Cause and Potential Target of Axonal Neuropathy in Type 2 Charcot-Marie-Tooth Disease
}

\author{
(1)Gursimran Chandhok ${ }^{\star}$ and $\oplus^{-M i n g}$ Shiuan Soh* \\ Neuroscience Program, Monash Biomedicine Discovery Institute, and Department of Anatomy and Developmental Biology, Monash University, Clayton, \\ Victoria 3800, Australia \\ Review of Spaulding et al.
}

Charcot-Marie-Tooth (CMT) disease is a heterogeneous group of inherited disorders affecting the peripheral nervous system and characterized by distal motor and sensory dysfunction (Charcot and Marie, 1886; Tooth, 1886). Type 2 axonal CMT (CMT2) accounts for $\sim 20 \%$ of all CMT cases, and it causes progressive muscle weakness and wasting, with sensory deficits in distal limbs resulting from peripheral axon degeneration (Murakami et al., 1996; Fledrich et al., 2012). Because of its phenotypic and genetic heterogeneity, the pathogenesis of CMT remains poorly understood. Despite first being described more than a century ago, there is still no effective treatment for the disease.

The study by Spaulding et al. (2016) focused on axonal type 2D CMT (CMT2D), which is caused by dominant mutations in the Glycyl tRNA synthetase (GARS) gene (Antonellis et al., 2003; Griffin et al., 2014). Although several attempts have been made to correlate specific genotypes with phenotypes observed in CMT2D, how a ubiqui-

\footnotetext{
Received May 9, 2016; revised June 19, 2016; accepted June 23, 2016. We thank Dr. Brent Neumann for his advice on the paper. The authors declare no competing financial interests.

${ }^{*}$ G.C. and M.S.S. contributed equally to this work.

Correspondence should be addressed to Dr. Gursimran Chandhok, Neuroscience Program, Monash Biomedicine Discovery Institute, and Department of Anatomy and Developmental Biology, Monash University, Clayton, Victoria 3800, Australia. E-mail: gursimran.chandhok@gmail.com. DOI:10.1523/JNEUROSCI.1515-16.2016

Copyright $\odot 2016$ the authors $\quad 0270-6474 / 16 / 368067-03 \$ 15.00 / 0$
}

tously expressed protein necessary for protein translation results selectively in axonal neuropathy remains unclear. To understand the cellular and molecular mechanism linking GARS to CMT2D, Spaulding et al. (2016) used two mouse models with Gars mutations, Gars ${ }^{\text {P278KY }}$ and Gars ${ }^{C 201 R}$, both of which have motor and sensory deficits of varied severity similar to those observed in patients. Mice carrying the Gars ${ }^{C 201 R}$ allele (GARS $S^{C 157 R}$ in humans), exhibits the same traits as Gars ${ }^{P 278 K Y}$ mice, but with less severity (Achilli et al., 2009). Spaulding et al. (2016) found that both mutant strains displayed a loss of neuromuscular junction (NMJ) integrity, which was attributed to presynaptic deficits. Although previous research has identified the NMJ as an early and important site in neuropathology, it has not been considered a major site of CMT pathology (Sleigh et al., 2014). Nevertheless, NMJ loss has also been reported in type 1 CMT mouse models (Ang et al., 2010), indicating that this may be a common mechanism of disease. The presence of NMJ abnormalities suggests that more detailed study of the pathological events occurring at these sites will provide a greater understanding of the mechanisms underlying CMT, possibly identifying new therapeutic targets.

To address whether weakened synaptic transmission at NMJ contributes to CMT2D, Spaulding et al. (2016) analyzed the relatively mildly affected proximal le- vator auris longus (LAL) muscles on the dorsal surface of the head. Notably, the authors did not use muscles in the distal limb region that are normally affected in CMT and commonly studied in similar mouse strains (Seburn et al., 2006; Achilli et al., 2009; Sleigh et al., 2014), thus hindering comparisons between proximal and distal pathologies. Given that distal limb muscles showed a significantly higher severity of neuropathy and axonal loss than proximal muscles in Gars ${ }^{P 278 K Y}$ mice (Seburn et al., 2006) the use of only proximal muscles may not provide the best representation of CMT2D pathophysiology. Because patients rarely present with muscle atrophy and weakness in the dorsal head regions, it is difficult to correlate the observed NMJ dysmorphology in the LAL muscles of the mutant mouse with the absence of pathological symptoms in the human equivalent muscles. To justify the use of proximal muscles for studying CMT2D, it would be important to compare the pathophysiology of both types of muscles before proceeding to focus on just the proximal muscles.

Nevertheless, within these limitations, Spaulding et al. (2016) compared NMJ synaptic properties and treatment responses in two CMT2D mouse models. They found that synaptic defects in proximal LAL muscles varied with disease severity $\left(\right.$ Gars $^{P 278 K Y}$ more severe than 
Gars $^{C 201 R}$ ). This study adds to accumulating evidence that functional NMJ changes vary across genotype and age, independent of the specific mutations. Although spontaneous miniature endplate currents were unperturbed in both strains regardless of age, the spontaneous neurotransmitter release rate, quantal content, and evoked endplate currents (EPCs) were considerably reduced, more so in the severe Gars $^{P 278 K Y}$ animals than the milder Gars $^{C 201 R}$ strain. The reduction in quantal content was consistent with morphological abnormalities of partial or complete denervation of the terminals. These deficits were attributed to a presynaptic rather than a postsynaptic defect at NMJ in CMT2D mice.

Next, Spaulding et al. (2016) assessed whether modulating synaptic transmission could ameliorate the muscle weakness observed in CMT2D mice. To this end, the authors first tested 3,4-diaminopyridine (3,4-DAP), which modulates presynaptic acetylcholine release. 3,4DAP effectively treats Lambert-Eaton myasthenic syndrome (Sanders, 1998; Lindquist and Stangel, 2011), another disease characterized by muscle weakness in the limbs and autonomic dysfunctions. 3,4-DAP acts by blocking potassium channels in nerve terminals, resulting in an increase in acetylcholine release (Fig. $1 A)$. Reduced quantal release of acetylcholine was observed in CMT2D mice and hence, administration of 3,4-DAP was expected to increase acetylcholine release, thereby improving muscle strength. Surprisingly however, 3,4-DAP did not improve wire-hang time in 1- or 4-month-old Gars ${ }^{\text {C201R }}$ mice, despite improvements in the average presynaptic neurotransmitter release and EPCs (Spaulding et al., 2016). Spaulding et al. (2016) reasoned that these synaptic enhancements were short-lived, and therefore insufficient to compensate for the synaptic deficits. Worse still, the presence of 3,4-DAP during the final stimulus significantly reduced both the quantal release and EPC in Gars ${ }^{C 201 R}$ mice. This deteriorating performance appeared inconsistent with the mechanism of action for 3,4-DAP at the given dose. The lack of improvement for the CMT2D mutants' in their wire-hang performance suggests that: (1) the presynaptic quantal release deficit was not the underlying cause of CMT2D muscle weakness; (2) there are other factors in addition to presynaptic deficits that contribute to the overall distal muscle weakness, hence the administration of 3,4-DAP alone was insufficient or

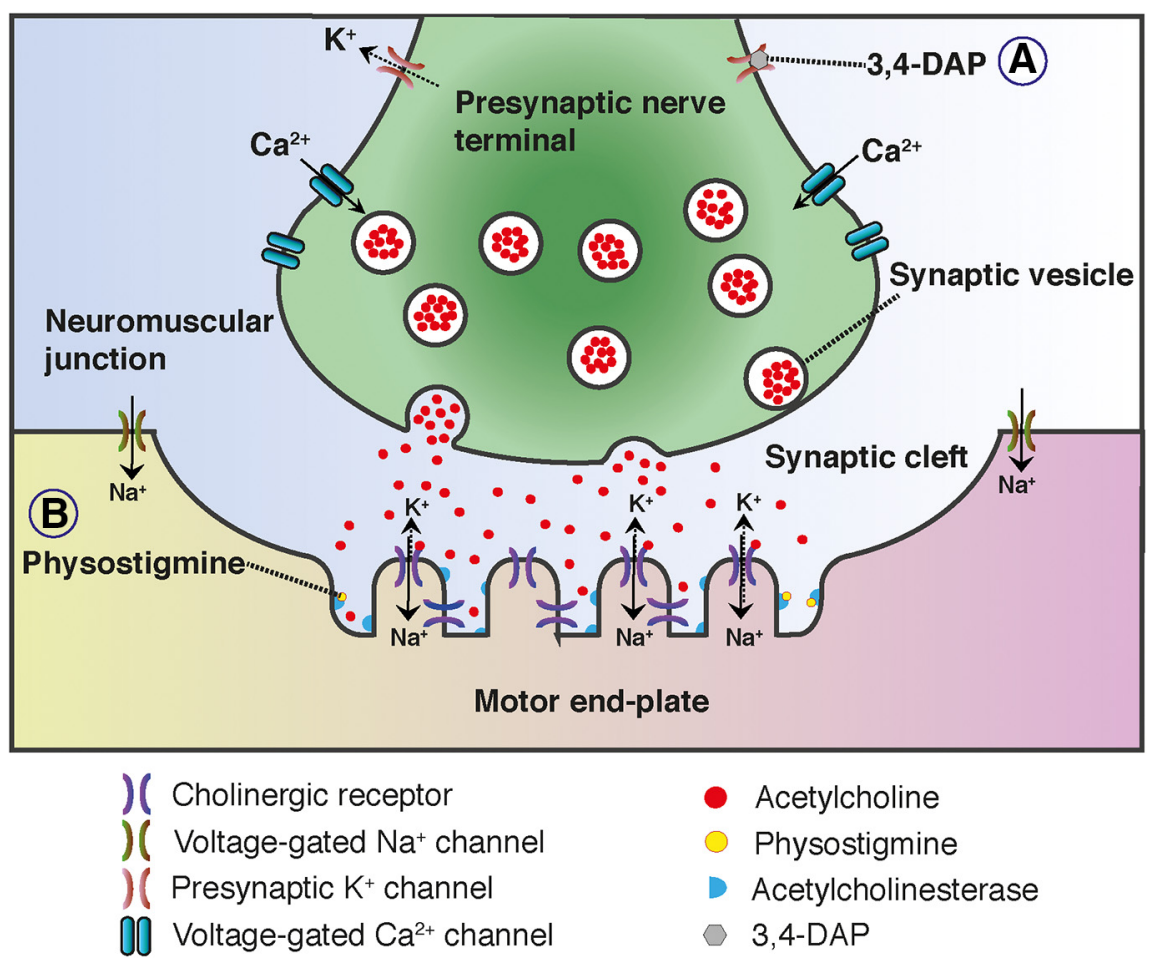

Figure 1. Mechanisms of action for 3,4-DAP and physostigmine. A, 3,4-DAP blocks $\mathrm{K}^{+}$channel efflux in presynaptic nerve terminals, resulting in an increased duration of presynaptic action potential. This increases the opening time of $\mathrm{Ca}^{2+}$ channels, which induces greater acetylcholine release from presynaptic vesicles. However, 3,4-DAP failed to improve wire-hang times in

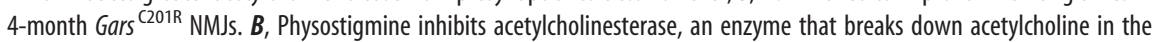
synaptic cleft. Physostigmine improved wire-hang times in 4-month Gars ${ }^{\mathrm{C201R}} \mathrm{NMJs}$. Both physostigmine and 3,4-DAP can be used to increase EPC amplitude in 4-month old Gars ${ }^{\mathrm{C201R}}$ NMJs.

detrimental; (3) 3,4-DAP could not bind properly to $\mathrm{K}^{+}$channels at presynaptic nerve terminals due to membrane structure defects; and/or (4) the $2.5 \mathrm{mg} / \mathrm{kg} \mathrm{3,4-}$ DAP used in CMT2D mutant mice was not therapeutically relevant. In fact, the effective dose of 3,4-DAP approaches 8 $\mathrm{mg} / \mathrm{kg}$ for other conditions involving deficits in presynaptic acetylcholine release (Siegel et al., 1986). Thus, it would be useful to perform dose-response studies of 3,4-DAP with increasing drug concentrations before completely ruling out the effectiveness of the drug.

Interestingly, despite strong evidence supporting presynaptic defects in the CMT2D models (Spaulding et al., 2016), both mice strains performed better on administration of the postsynaptically acting drug physostigmine. Physostigmine is a reversible inhibitor of acetylcholinesterase, the enzyme responsible for the breakdown of acetylcholine in the synaptic cleft (Fig. $1 B)$. Clinically, physostigmine is used to treat cholinergic disorders and myasthenia gravis, but has a short half-life and narrow therapeutic index (Yu et al., 2010; Mehta et al., 2012). Future investigations with other acetylcholinesterase inhibitors (for instance pyridostigmine and neostigmine) with bet- ter potency and efficacy than physostigmine might help translate the findings to patients with CMT2D. Repeating the behavioral studies with other similar compounds is crucial to ensure the beneficial effect of acetylcholinesterase inhibitors before proceeding to therapeutic application in CMT2D humans. It would also be valuable to study the combination of presynaptically and postsynaptically acting drugs in CMT2D mouse models to determine whether there is a synergistic effect of the drugs. In fact, the combination of 3,4-DAP and the cholinesterase inhibitor pyridostigmine produced a better therapeutic outcome in LambertEaton myasthenic syndrome than either treatment alone (Lundh et al., 1984).

Together, although the work by Spaulding et al. (2016) has provided insights into the NMJ defects occurring in CMT2D, we still lack a clear explanation for how the GARS mutations lead to selective neuronal pathology. Previous studies have demonstrated that although the overexpression of wild-type GARS could completely rescue the embryonic lethality caused by mutant GARS, the neuropathy could not be improved. This suggests that neuropathy is the result of a dominant and toxic gain-offunction that cannot be compensated by the 
wild-type protein (Motley et al., 2011; Grice et al., 2015). Furthermore, He et al. (2015) found that several GARS mutants, including Gars $^{P 278 K Y}$ in mice, attained a neomorphic ability to bind to the neuropilin 1 (Nrp1) receptor, which prevented the binding of Nrp1 to vascular endothelial growth factor (VEGF). As the Nrp1 receptor is involved in motor neuron axon pathfinding and stabilization of neuronal cytoskeleton (Huber et al., 2005; Moloney et al., 2014), and the impairment of the VEGF-Nrp1 signaling pathway causes selective motor neuron degeneration in mice (Oosthuyse et al., 2001), it is possible that GARS mutation can disrupt proper axonal guiding and cause cytoskeletal destabilization in motor neurons. Consequently, nerve terminals may be weakly formed, resulting in presynaptic deficits and NMJ denervation. Overexpression of VEGF has previously been shown to rescue the motor function in CMT2D mice (He et al., 2015). However, treatment of patients with VEGF is not recommended because it can also promote tumorigenesis (Goel and Mercurio, 2013). It will therefore be intriguing to focus future investigations on the relationship between the anomalous gain-of-function by mutant synthetases, NMJ defects, and role of acetylcholinesterase inhibitors in rescuing the motor function in CMT2D models. It will also be worthwhile to explore the influence of GARS mutations on Nrp1 signaling and presynaptic deficits, and investigate whether modulation of the Nrp-1-VEGF signaling pathway can improve peripheral neuropathy. The knowledge afforded by the current study, especially motor defects reversal by physostigmine, opens the door for future investigations to develop new therapeutic strategies for CMT2D. Overall, the work by Spaulding et al. (2016) suggests a presynaptic defect at the NMJ and unearths new avenues for the development of treatments for CMT2D, and potentially other axonal forms of CMT.

\section{References}

Achilli F, Bros-Facer V, Williams HP, Banks GT, AlQatari M, Chia R, Tucci V, Groves M, Nickols CD, Seburn KL, Kendall R, Cader MZ, Talbot K, van Minnen J, Burgess RW, Brandner S, Martin JE, Koltzenburg M, Greensmith L, Nolan PM, Fisher EM (2009) An ENU-induced mutation in mouse glycyl-tRNA synthetase
(GARS) causes peripheral sensory and motor phenotypes creating a model of CharcotMarie-Tooth type 2D peripheral neuropathy. Dis Model Mech 2:359-373. CrossRef Medline

Ang ET, Schäfer R, Baltensperger R, Wernig A, Celio M, Oliver SS (2010) Motor axonal sprouting and neuromuscular junction loss in an animal model of Charcot-MarieTooth disease. J Neuropathol Exp Neurol 69:281-293. CrossRef Medline

Antonellis A, Ellsworth RE, Sambuughin N, Puls I, Abel A, Lee-Lin SQ, Jordanova A, Kremensky I, Christodoulou K, Middleton LT, Sivakumar K, Ionasescu V, Funalot B, Vance JM, Goldfarb LG, Fischbeck KH, Green ED (2003) Glycyl tRNA synthetase mutations in Charcot-Marie-Tooth disease type 2D and distal spinal muscular atrophy type V. Am J Hum Genet 72:1293-1299. CrossRef Medline

Charcot JM, Marie P (1886) Sur une forme particulière d'atrophie musculaire progressive, souvent familiale, debutant par les pieds et les jambes et atteignant plus tard les mains. Rev Med 6: 97-138.

Fledrich R, Stassart RM, Sereda MW (2012) Murine therapeutic models for CharcotMarie-Tooth (CMT) disease. Br Med Bull 102: 89-113. CrossRef Medline

Goel HL, Mercurio AM (2013) VEGF targets the tumour cell. Nat Rev Cancer 13:871-882. CrossRef Medline

Grice SJ, Sleigh JN, Motley WW, Liu JL, Burgess RW, Talbot K, Cader MZ (2015) Dominant, toxic gain-of-function mutations in gars lead to non-cell autonomous neuropathology. Hum Mol Genet 24:4397-4406. CrossRef Medline

Griffin LB, Sakaguchi R, McGuigan D, Gonzalez MA, Searby C, Züchner S, Hou YM, Antonellis A (2014) Impaired function is a common feature of neuropathy-associated glycyl-tRNA synthetase mutations. Hum Mutat 35:13631371. CrossRef Medline

He W, Bai G, Zhou H, Wei N, White NM, Lauer J, Liu $\mathrm{H}$, Shi Y, Dumitru CD, Lettieri K, Shubayev V, Jordanova A, Guergueltcheva V, Griffin PR, Burgess RW, Pfaff SL, Yang XL (2015) CMT2D neuropathy is linked to the neomorphic binding activity of glycyl-tRNA synthetase. Nature 526:710-714. CrossRef Medline

Huber AB, Kania A, Tran TS, Gu C, De Marco Garcia N, Lieberam I, Johnson D, Jessell TM, Ginty DD, Kolodkin AL (2005) Distinct roles for secreted semaphorin signaling in spinal motor axon guidance. Neuron 48:949-964. CrossRef Medline

Lindquist S, Stangel M (2011) Update on treatment options for Lambert-Eaton myasthenic syndrome: focus on use of amifampridine. Neuropsychiatr Dis Treat 7:341-349. CrossRef Medline

Lundh H, Nilsson O, Rosén I (1984) Treatment of Lambert-Eaton syndrome. Neurology 34: 1324-1330. CrossRef Medline

Mehta M, Adem A, Sabbagh M (2012) New ace- tylcholinesterase inhibitors for Alzheimer's disease. Int J Alzheimers Dis 2012:728983. CrossRef Medline

MoloneyEB, deWinter F, Verhaagen J (2014) ALS as a distal axonopathy: molecular mechanisms affecting neuromuscular junction stability in the presymptomatic stages of the disease. Front Neurosci 8:252. CrossRef Medline

Motley WW, Seburn KL, Nawaz MH, Miers KE, Cheng J, Antonellis A, Green ED, Talbot K, Yang XL, Fischbeck KH, Burgess RW (2011) Charcot-Marie-Tooth-linked mutant GARS is toxic to peripheral neurons independent of wild-type GARS levels. PLoS Genetics 7: e1002399. CrossRef Medline

Murakami T, Garcia CA, Reiter LT, Lupski JR (1996) Charcot-Marie-Tooth disease and related inherited neuropathies. Medicine (Baltimore) 75:233-250. CrossRef Medline

Oosthuyse B, Moons L, Storkebaum E, Beck H, Nuyens D, Brusselmans K, Van Dorpe J, Hellings $\mathrm{P}$, Gorselink M, Heymans S, Theilmeier G, Dewerchin M, Laudenbach V, Vermylen P, Raat H, Acker T, Vleminckx V, Van Den Bosch L, Cashman N, Fujisawa $\mathrm{H}$, et al. (2001) Deletion of the hypoxia-response element in the vascular endothelial growth factor promoter causes motor neuron degeneration. Nat Genet 28:131-138. CrossRef Medline

Sanders DB (1998) 3,4-Diaminopyridine (DAP) in the treatment of Lambert-Eaton myasthenic syndrome (LEMS). Ann N Y Acad Sci 841:811-816. CrossRef Medline

Seburn KL, Nangle LA, Cox GA, Schimmel P, Burgess RW (2006) An active dominant mutation of glycyl-tRNA synthetase causes neuropathy in a Charcot-Marie-Tooth $2 \mathrm{~d}$ mouse model. Neuron 51:715-726. CrossRef Medline

Siegel LS, Johnson-Winegar AD, Sellin LC (1986) Effect of 3,4-diaminopyridine on the survival of mice injected with botolinum neurotoxin type A, B, E, or F. Toxicol Appl Pharmacol 84:255-263. CrossRef Medline

Sleigh JN, Grice SJ, Burgess RW, Talbot K, Cader MZ (2014) Neuromuscular junction maturation defects precede impaired lower motor neuron connectivity in Charcot-Marie-Tooth type 2D mice. Hum Mol Genet 23:2639-2650. CrossRefMedline Spaulding EL, Sleigh JN, Morelli KH, Pinter MJ, Burgess RW, Seburn KL (2016) Synaptic deficits at neuromuscular junctions in two mouse models of Charcot-Marie-Tooth type 2d. J Neurosci 36: 3254-3267. CrossRef Medline

Tooth HH (1886) The peroneal type of progressive muscular atrophy. London: HK Lewis.

Yu QS, Holloway HW, Luo W, Lahiri DK, Brossi A, Greig NH (2010) Long-acting anticholinesterases for myasthenia gravis: synthesis and activities of quaternary phenylcarbamates of neostigmine, pyridostigmine and physostigmine. Bioorg Med Chem 18:4687-4693. CrossRef Medline 